\title{
Allergic skin conditions - causes, clinical features and treatment
}

\author{
Hendrick M. Motswaledi \\ Department of Dermatology, Sefako Makgatho Health Sciences University \\ *Corresponding author, email: motswaledi1@webmail.co.za
}

\section{Abstract}

Allergic skin conditions are caused by allergens. When an allergen is responsible for triggering an immune system response, this results in an allergic skin condition. Some of these allergens are physical agents which evoke an immune response by way of contact with the skin and some are food-stuffs and drugs taken systemically.

Allergic skin conditions include urticaria and angio-oedema, allergic contact dermatitis, atopic dermatitis, hand dermatitis, photoallergic reactions and phototoxic reactions. These conditions are briefly discussed in this article.

Keywords: Allergic skin conditions, allergy, allergens

\section{Urticaria and angio-oedema}

Urticaria is a transient eruption of erythematous, or oedematous swellings of the dermis, often associated with itching ${ }^{1}$. It is also called weals or hives.

Urticaria is classified as acute, if it is present daily or almost daily for less than 6 weeks, and chronic if it occurs continuously on most days for longer than 6 weeks ${ }^{2}$. Urticaria can be due to allergens like drugs and foodstuffs hence the term allergic urticaria.

Other rare types of urticaria are immune-complex urticaria, physical urticaria, urticarial vasculitis and contact urticaria.

Allergic urticaria is IgE mediated. IgE binds to mast cells and they release histamine which causes increased vascular permeability. Activation of $\mathrm{H}-1$ receptors in the skin induces itching, flare, erythema and wealing.

Typical lesions of urticaria are itching, erythematous weals consisting of pale-pink, oedematous raised skin lesions often with a surrounding flare (Figure 1). They occur anywhere on the body in variable sizes and numbers. The shape of the lesions may be round, annular, serpiginous and bizarre patterns ${ }^{1}$. Lesions are itchy and patients tend to rub rather than scratch.

Common causes of acute allergic urticaria are drugs like penicillins, cephalosporines, tetracyclines and sulphonamides, as well as food-stuffs like crustaceans, fish, nuts, beans and spices. Usually reactions of acute allergic urticaria occur within minutes to hours after drug or food ingestion.

Acute allergic urticarial lesions are often transient, lasting for a few hours and resolve within 24 hours. By the time the patient presents to a clinician the lesions may be gone.

Angio-oedema is a variant of urticaria in which the swelling involves deeper subcutaneous and submucosal tissues. ${ }^{3}$ It affects any part of the body but commonest sites are genitalia, eyelids and lips.

Lesions may be single or multiple and may appear suddenly. Angio-oedema lesions usually do not itch and they last for a few hours.

Treatment of acute allergic urticaria and angio-oedema involves short courses of systemic steroids and antihistamines.

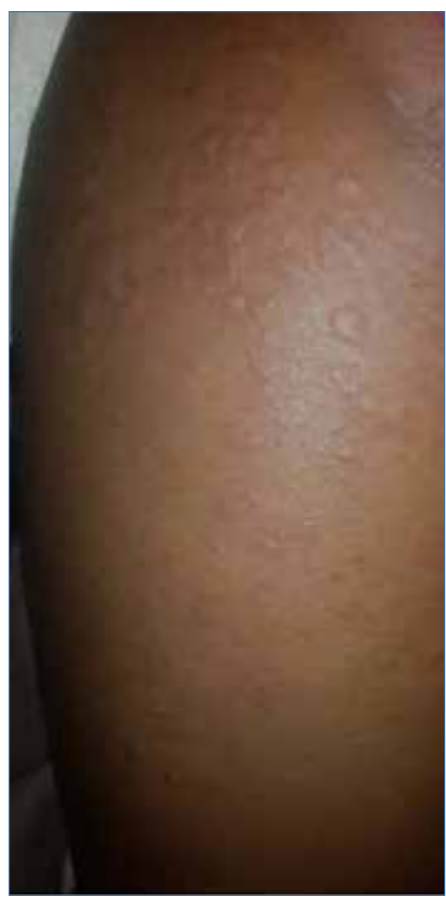

Figure 1: Urticaria on the thigh

\section{Allergic contact dermatitis}

Allergic contact dermatitis is a common disease resulting from exposure to objects or chemicals in a patient's personal care products, home or work environment referred to as allergens. ${ }^{4}$ An allergen is any substance most often eaten, touched or inhaled that is recognised by the immune system and causes an allergic reaction.

Allergic contact dermatitis is a delayed type hypersensitivity reaction that is elicited when the skin or mucous membranes 
come in contact with an allergen to which an individual has previously been sensitised. ${ }^{5}$

It has to be differentiated from irritant contact dermatitis which is the result of a local toxic effect when the skin comes in contact with irritant chemicals, such as solvents, acids or alkali.

Common allergens which cause allergic contact dermatitis may be jewellery, leather, personal care products like soaps and fragrances, plants, herbal medications, as well as objects or chemicals at work.

Allergic contact dermatitis can be acute or chronic. Clinically, it presents as well demarcated erythematous, vesicular or scaly patch or plaque with well-defined margins corresponding to the area of contact (Figure 2).

Acute episodes may present with a rash, blistering, weeping and oedema. Chronic episodes present with lichenified or scaly plaques. Allergic contact dermatitis is a delayed type hypersensitivity response that is allergen specific and requires prior sensitization of the individual to the allergen in question. When the patient first comes in contact with the allergen sensitization occurs. During the subsequent re-exposure there is release of cytokines and chemotactic factors resulting in a dermatitis. $^{5}$

Even products that have been used before for some years can result in allergic contact dermatitis, either because of change in product formulation or as a result of sensitization to the product over time. ${ }^{4}$ Contributing factors towards development of allergic contact dermatitis are decreased skin barrier function, friction, heat and sweating. ${ }^{4}$

Common causes of allergic contact dermatitis are poison ivy and nickel (Figure 3). In most cases, it is a clinical diagnosis but patch testing is a gold standard in diagnosing allergic contact dermatitis. $^{6}$

\section{Patch testing}

Patch testing is indicated in any patient presenting with a chronic, pruritic, eczematous or lichenified dermatitis, if allergic contact dermatitis is suspected. ${ }^{6,7}$

When a particular allergen is not suspected, then a preloaded commercially available allergen kit can be used. If a particular allergen is suspected, e.g. a chemical substance at work, then the patch test is performed with a sample of that chemical.

Patch tests are often performed at the back or on the forearm (Figure 4). The area should be cleaned with water, and allowed to dry. Patch test chamber is applied and closed with adhesive tape. Results are read after 48 hours or earlier if a severe reaction with marked irritation occurs.

Patch test results can be negative, doubtful reaction, weakly positive, strongly positive or extremely positive. ${ }^{6,7}$

False-positive results can result from the use of irritants or allergic substances at potentially irritating higher concentrations. ${ }^{6}$

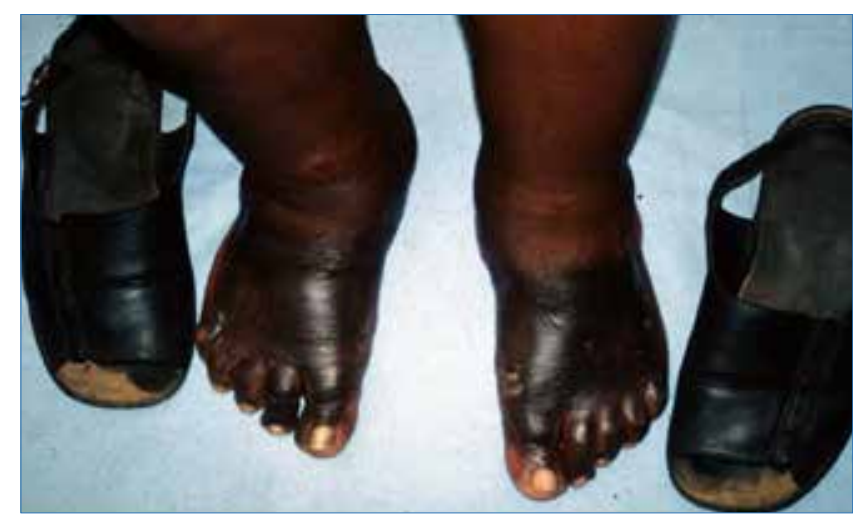

Figure 2: Allergic contact dermatitis due to shoes

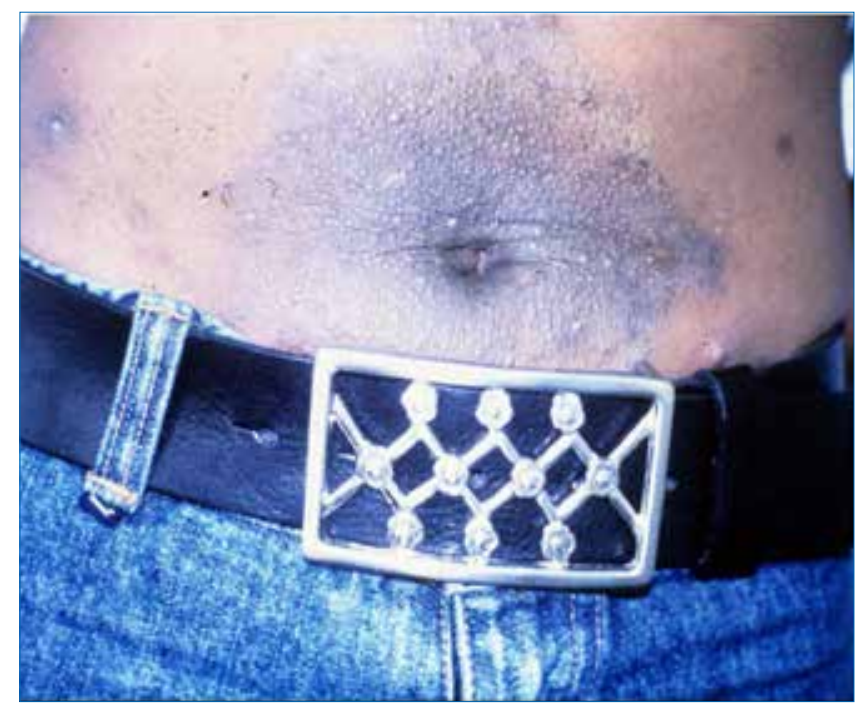

Figure 3: Nickel dermatitis due to buckle of belt

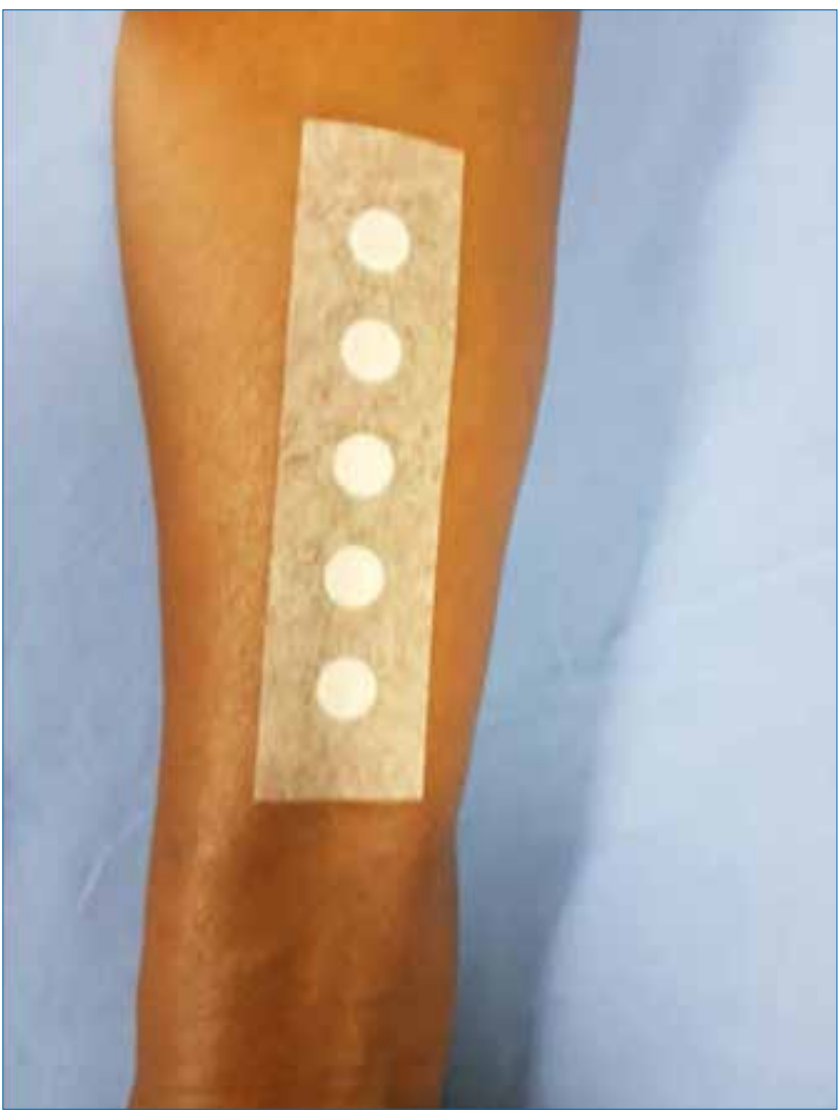

Figure 4: Patch test on the forearm 


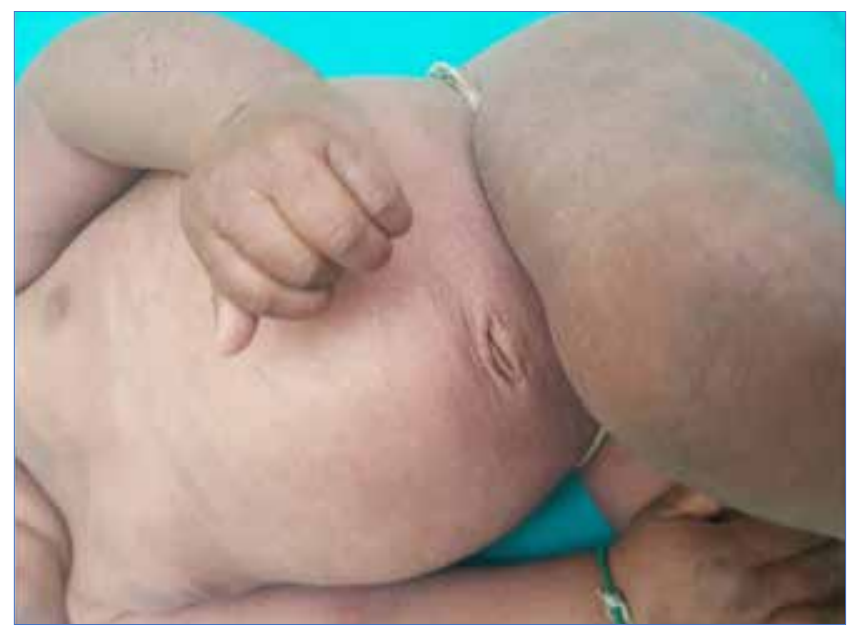

Figure 5: Atopic dermatitis in an infant

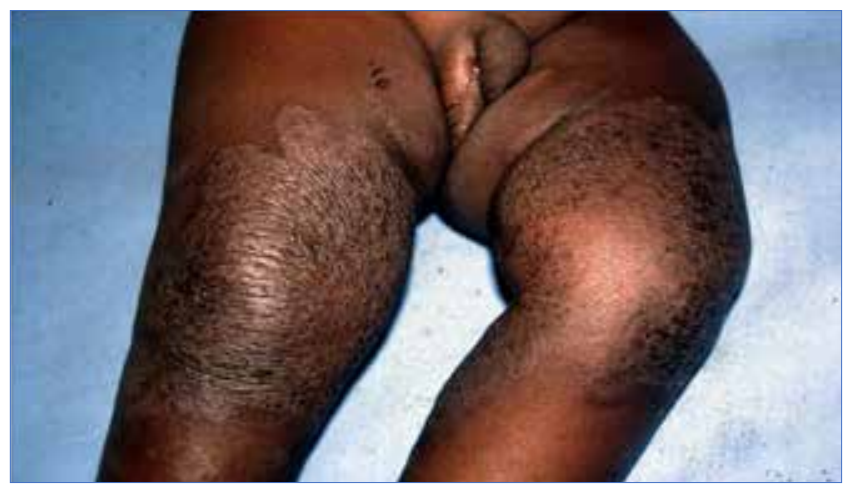

Figure 6: Atopic dermatitis on extensor aspect of legs

False-negative reactions may be due to too low concentrations of the allergen used. Other factors which may tamper with patch test reactions are prior ultraviolet light exposure to the test area, use of topical or systemic corticosteroids, topical calcineurin inhibitors and concomitant immunosuppressive therapies. ${ }^{6}$

Patch testing is a delayed-type hypersensitivity reaction that differs from skin prick testing which tests for an immediate hypersensitivity reaction. Patch testing leads to skin rashes while skin prick tests lead to rhinorrhoea, eye tearing and shortness of breath. ${ }^{4}$

Side effects of patch tests include pruritus at site of positive reaction, infections and anaphylaxis. In rare cases, a patient may develop widespread multiple positive patch tests reactions, a phenomenon called excited skin syndrome or angry back syndrome. ${ }^{4}$

Treatment of allergic contact dermatitis starts with identification of the allergen and avoidance thereof. Application of potent topical corticosteroids often results in resolution of the lesions.

\section{Atopic dermatitis}

Atopic dermatitis (atopic eczema) is an itchy, chronic, relapsing inflammatory skin condition, characterised by itchy papules which become excoriated and lichenified and often have a flexural distribution. ${ }^{8}$

It is often associated with other atopic diseases, like asthma, allergic rhinitis and allergic conjuctivitis. The pathogenesis of

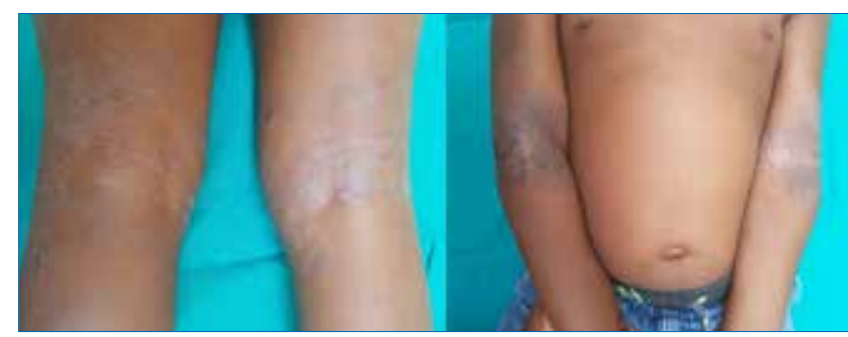

Figure 7: Atopic dermatitis on flexor aspect of limbs

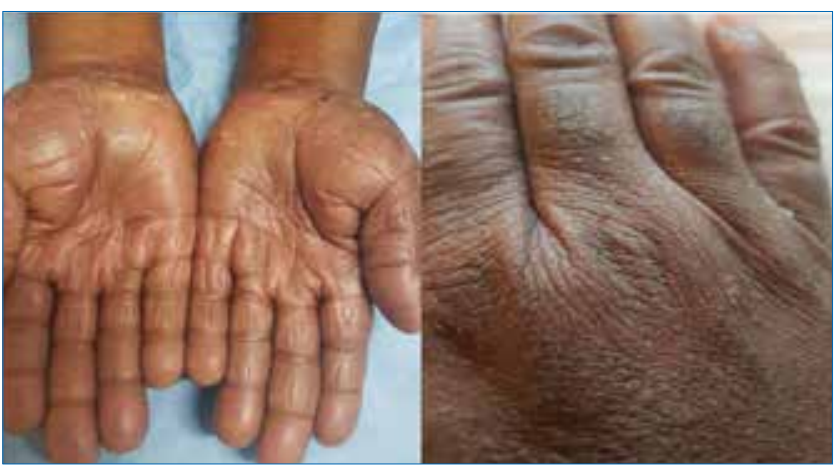

Figure 8: Hand dermatitis, palmar and dorsal aspects

atopic eczema involves many factors including genetic factors, allergies, infections, climatic and environmental influences. ${ }^{8}$ Environmental allergens are probably the major determinants of whether sensitization of genetically predisposed individuals occurs. ${ }^{8}$

The two most considered environmental allergens are pollution and microbes. ${ }^{8}$ In individuals with the atopic phenotype, eczema may be induced or exacerbated by staphylococcal toxins or by the presence on the skin of Malassezia yeasts. ${ }^{8}$

Colonization of the skin by staphylococcus aureus exacerbates eczema by way of staphylococcal superantigens which drive an inflammatory response and elicit an eczematous inflammatory reaction. Secondly, invasive infection by staphylococci produces acute, infected flares of eczema. ${ }^{8}$

Atopic dermatitis patients mount IgE antibody responses to a variety of environmental allergens. ${ }^{9}$

The clinical presentation of atopic eczema varies with age.

In infants, the rash may occur all over the body with a nonspecific distribution (Figure 5).

In crawling children, the extensor aspects of the knees and elbows are mostly affected (Figure 6). In older children, the flexural aspects of elbows, knees and wrists are characteristically involved (Figure 7).

In adults, the clinical picture is like that of an older child with lichenification of flexures. Lesions in atopic dermatitis may be vesicular, weeping and crusted in acute stage or erythematous papules, excoriations and lichenifications in subacute and chronic phases.

Treatment of atopic dermatitis is beyond the scope of this article, but involves the use of emollients, topical corticosteroids, topical 
calcineurin inhibitors, phototherapy and immunosuppressive drugs in recalcitrant cases. $8,10,11$

\section{Hand dermatitis}

It is a pruritic inflammatory skin disease characterised in the acute phase by erythema, oedema and sometimes vesicles, and in the chronic phase by scaling and sometimes fissuring. ${ }^{12}$

Hand dermatitis is largely confined to the hands. There may be minor involvement of other areas. Risk factors for hand dermatitis include hereditary factors, atopic dermatitis, occupational exposure to contact allergens, such as chemicals, epoxy glues and rubber. Certain occupations are particularly predisposing to hand dermatitis, e.g. hair dressers, fish industry workers, dental and medical personnel, metal workers and caterers. About 30\% of occupational medical practice relates to hand dermatitis with medical litigation, worker compensation and disability. ${ }^{13}$ Hand dermatitis may affect palmar surfaces, dorsal aspect of hands or both (Figure 8).

For cases of occupational exposure, protective clothing and gloves are required.

\section{Photo-allergic reactions}

Photo-allergic reactions occur when exposure to ultraviolet light alters the structure of a drug and stimulates the immune system to react. These reactions require a latent period during which sensitization occurs and usually appear within 24 hours of reexposure to a drug and light in a sensitised person. ${ }^{14}$

Clinically photo-allergic reactions occur on sun-exposed areas with erythema, itching and swelling in acute cases.

Unlike phototoxic reactions, photo-allergic reactions may spread beyond irradiated areas.

Photo-allergic reactions may be triggered by topically applied fragrances, medications, and sunscreens.

Photo-allergic reactions may also occur as a result of systemic drugs like phenothiazines, sulphonamides, thiazide diuretics and oral hypoglycaemic agents. ${ }^{14}$

Treatment involves avoidance of the cause and application of potent topical corticosteroids and photo-protection.

Photo-allergic reactions take some time to resolve.

\section{Photo-toxic reactions}

Photo-toxic dermatitis is an inflammatory, photochemically evoked skin reaction caused by concomitant exposure to the sun and photosensitising substances, which increase the reactivity of the skin to ultraviolet radiation. ${ }^{15}$
These are reactions which occur when ultraviolet $\mathrm{A}$ radiation combines with photosensitising topical agents, mainly from plants or oral medications to produce skin markings which resemble a severe sunburn. The sunburn-like lesions typically present on sun exposed areas with erythema, oedema and in severe cases blistering. ${ }^{15}$ Phototoxic reactions occur quickly within 24 hours of exposure to the skin, unlike photoallergic reactions which need some time for an individual to be sensitised. Phototoxic reactions occur commonly in children when playing scantily clad in gardens and shrubs. ${ }^{16}$

While photo allergic reactions are rare and only occur in susceptible individuals, phototoxic reactions are more common and can be produced in almost all individuals given a high enough dose of drug and sufficient light irradiation. ${ }^{14}$

Treatment involves avoidance of the cause and application of potent topical corticosteroids.

\section{References}

1. Black AK, Champion RH. Urticaria. In: Champion RH, Burton JL, Burns DA and Breathnach SM, eds. Rook's textbook of Dermatology, 6th ed. Oxford. Blackwell Science, 1998; p. 2113-39.

2. Grattan CEH, Black AK. Urticaria and Mastocytosis. In: Burns T, Breathnach SM, Cox N and Griffiths $C$, eds. Rook's textbook of Dermatology, 8th ed Oxford. Wiley-Blackwell, 2010; p. 22.1-22.36.

3. Grattan CEH, Black AK. Urticaria and Angioedema. In: Bolognia JL, Jorizzo JL and Rapini RP, eds. Dermatology, 2nd ed. Spain. Mosby-Elsevier, 2008; p. 261-76.

4. Mowad CM, Anderson B, Scheinman P, Pootongkam S, et al. Allergic Contact dermatitis, patient management and education. J Am Acad Dermatol. 2016;74:1043-54.

5. Moward CM, Marks JG Jr. Allergic contact Dermatitis. In: Bolognia JL, Jorizzo JL and Rapini RP eds. Dermatology, 2nd ed. Spain. Mosby-Elsevier, 2008; p. 233-48.

6. Fonacier L. A Practical Guide to Patch Testing. Clinical Commentary Review. J Allergy Clin Immunol Pract. 2015;3:669-75.

7. Davis MD, Hylwa SA, Allen EM. Basics of Patch testing for Allergic Contact Dermatitis. Semin Cutan Med Surg. 2013;32:158-68.

8. Friedman PS, Arden-Jones MR, Holden CA. Atopic dermatitis. In: Burns T, Breathnach S, Cox N and Griffiths C, eds. Rook's Textbook of Dermatology, 8th ed. Oxford. Wiley - Blackwell, 2010; p. 24.1-24.34.

9. Lucae S, Schmid-Grendelmeier P, Wuthrich B, Kraft D, et al. IgE responses to exogenous and endogenous allergens in atopic dermatitis patients under long-term systemic cyclosporine: A treatment. Allergy. 2016;71:115-8.

10. Motswaledi MH. An overview of topical treatment for atopic eczema. S Afr Fam Pract. 2011;53(3):247-9.

11. Motswaledi MH. An approach to mild to moderate atopic eczema. S Afr Fam Pract. 2012;54(5):411-2.

12. Mollerup A, Veien NK, Johansen JD. Chronic hand eczema - self management and prognosis: a study protocol for a randomised clinical trial. BMC Dermatology. 2012;12(6):1-9.

13. Berth-Jones J. Eczema, lichenification, Prurigo and Erythroderma. In: Burns $T$, Breathnach S, Cox N and Griffiths C, eds. Rook's textbook of Dermatology, 8th ed. Oxford. Wiley - Blackwell, 2010; p. 21.1-23.51.

14. Breathnach SM. Drug Reactions. In: champion RH, Burton JL, Burns DA, Breathnach SM, eds. Rock of Wilkinson/Ebling Textbook of Dermatology, 6th ed. Oxford. Blackwell Science, 1998; p. 3349-17.

15. Baden LR. Phototoxic Dermatitis. N Engl J Med. 2014;371(6):559.

16. Lovell CR. Phytodermatoses. In: Harper J, Orange A and Prose M, eds. Textbook of Paediatric Dermatology. Oxford. Blackwell Science, 2000; p. 295-303. 